\title{
OPEN Effect of extraction temperature and solvent type on the bioactive potential of Ocimum gratissimum L. extracts
}

\author{
Confidence Onyebuchi ${ }^{1 \bowtie}$ \& Doğa Kavaz ${ }^{1,2}$
}

Ocimum gratissimum is a shrub that belongs to the Lamiaceae family of plants. Despite the known biological activities and ethnomedicinal applications, comparative evaluation of the effects of different extraction techniques on the chemical and bioactive properties of $O$. gratissimum extracts has not yet been performed. This study adopted different analytical techniques to determine the effect of extraction temperature and solvent type on the phytochemical and bioactive properties of 0 . gratissimum extracts. Chemical profiling showed increased concentrations of compounds for both the ethanolic and methanolic extracts compared to the water extracts. The results also revealed that the extraction temperature had an effect on the total phenolic content and radical-scavenging properties of the different extracts. The antioxidant kinetic modeling achieved the best fit when using the second-order kinetic model. Methanolic extracts had the highest levels of antibacterial activity against Escherichia coli, Bacillus cereus, Staphylococcus aureus, and Salmonella typhimurium. At high concentrations, all extracts lowered the viability of the breast cancer cell line MDA-MB-231. In conclusion, the chemical and bioactive properties of all extracts showed significant dependence on the extraction temperature and solvent type. With proper extraction methods, they boast a wide range of promising applications in the medical, pharmaceutical, and food industries.

Microbial pollution is a global problem that is primarily caused by pathogenic bacteria such as Bacillus cereus, Escherichia coli, Salmonella typhimurium, and Staphylococcus aureus ${ }^{1}$. Recent studies have focused on the extraction of polyphenols from plants due to the antimicrobial ${ }^{2}$ and antioxidant ${ }^{3}$ effects of these compounds, as well as their ability to decrease food spoilage resulting from lipid oxidation without affecting the quality, safety, and freshness of the food product ${ }^{4,5}$. Moreover, a study by Shahidi and Zhong ${ }^{6}$ demonstrated the link between oxidative stress and the pathophysiology of several health conditions. Ocimum gratissimum L. often called clove basil or scent leaf, is indigenous to coastal, savannah, and tropical areas ${ }^{7}$, and is mostly found in tropical areas such as West Africa, Asia, Brazil, and India ${ }^{8}$. Ethnomedicinal applications have been reported for the plant due to its flowers and leaves being rich in polyphenols and other bioactive compounds ${ }^{9}$. Polyphenol isolation from plant sources can be achieved via several techniques. However, every technique has advantages and disadvantages. Hence, there is a need to ascertain which materials, techniques, and extraction conditions are optimal for polyphenol extraction, as the efficiency of the extraction process can affect the polyphenolic content and antioxidant capacity of the extract ${ }^{10}$. A universally acceptable protocol for extraction of polyphenols from plants would be difficult to establish due to the structural and compositional diversity of different plant phenolic compounds. Several variables, such as temperature and the nature of the solvent, may act independently or dependently to affect the extraction efficiency as well as the antioxidant capacity. Hence, there is a need to understand the mass transfer phenomenon for the extraction process using mathematical models. The use of kinetics and mathematical models facilitates the understanding of the mass transfer mechanism of the extraction process, which is essential for simulations, optimization, control, and design of the process and minimizes the number of experiments required ${ }^{11}$.

Although previous studies have reported the effects of different extraction solvents on the phytochemicals and bioactivity of plant extracts, none have developed extraction kinetic and phenomenological models for the effects of temperature variations and different common solvents (methanol, ethanol, and water) on the antioxidant and

\footnotetext{
${ }^{1}$ Bioengineering Department, Faculty of Engineering, Cyprus International University, Northern Cyprus via Mersin 10, 98258 Nicosia, Turkey. ${ }^{2}$ Biotechnology Research Centre, Cyprus International University, Northern Cyprus via Mersin 10, 99258 Nicosia, Turkey. ${ }^{\circledR}$ email: oukaeje@ciu.edu.tr
} 
antimicrobial capacity, inhibitory effect on cancer cell proliferation, and extraction efficiency of polyphenolics from O. gratissimum.

\section{Materials and methods}

Chemicals and instruments. Mueller-Hinton agar (MHA), 1-diphenyl-2-picrylhydrazyl (DPPH), Mueller-Hinton broth (MHB), methanol, ethanol, sodium carbonate, trolox, and Folin-Ciocâlteu reagent were purchased from Merck \& Co. (Kenilworth, NJ, USA). The instruments used include the gas chromatography-mass spectrometer (GCMS-QP2010 SE, Shimadzu Corporation, Kyoto, Japan), an ultraviolet-visible spectrophotometer (UV-2450; Shimadzu Corporation, Kyoto, Japan), Soxhlet apparatus, rotary evaporator, microscope (Leica DFC295), and cylinder crusher (XPC100; Tencan, Changsha County, China). O. gratissimum plant specimens were collected from the southern part of Nigeria. Identification of the plant was performed by the Department of Plant Science and Biotechnology, Abia State University, Uturu, Nigeria.

Preparation of the extracts. Prior to extraction, the plant material was dried indoors in the dark and subsequently crushed to achieve an average particle size of 3-5 $\mathrm{mm}$. The same particle size range was targeted for all extraction processes.

For the O. gratissimum ethanolic (OGE), methanolic (OGM), and water (OGW) extractions, $100 \mathrm{~g}$ of the crushed $O$. gratissimum leaves were placed in a Soxhlet apparatus. Following the addition of the solvent $(600 \mathrm{~mL})$, and the leaves were extracted for $6 \mathrm{~h}$ at $40^{\circ} \mathrm{C}, 50^{\circ} \mathrm{C}$, and $60^{\circ} \mathrm{C}$ for ethanolic and methanolic extractions. For extraction with water, the temperature used were $90^{\circ} \mathrm{C}, 100^{\circ} \mathrm{C}$, and $110^{\circ} \mathrm{C}$. The extraction temperatures for each solvent were chosen based on the boiling temperature of the solvent. After extraction, a rotary evaporator was used to recover the crude extract, which was freeze-dried prior to storage in a refrigerator $\left(4^{\circ} \mathrm{C}\right)$ until use.

Gas chromatography-mass spectrometry analysis of $\boldsymbol{O}$. gratissimum extracts. The chemical composition of the extracts was determined using gas chromatography-mass spectrometry (GC-MS), in a method modified from that reported by Kavaz et al. ${ }^{5}$. A fused-silica capillary column (film thickness: $30 \times 0.25$ HP-5Ms, $0.25 \mu \mathrm{m})$ was used for the determination of compounds, with helium acting as the carrier gas $(1 / \mathrm{mL}$ flow rate). An oven temperature of $40^{\circ} \mathrm{C}$ was set and held for $5 \mathrm{~min}$, then increased by $3{ }^{\circ} \mathrm{C} / \mathrm{min}$ up to $270{ }^{\circ} \mathrm{C}$. The split ratio was set at $60: 1$. The connection parts and ion sources were set at a temperature of $180^{\circ} \mathrm{C}$, and an interface temperature of $240{ }^{\circ} \mathrm{C}$ was set for the mass spectrometer. For the ionization energy amount, $70 \mathrm{eV}$ was adopted, while the electron impact (EI) mode was chosen to produce stable and reproducible mass spectra and a value range of $50-650 \mathrm{~m} / z$ was used for the running of samples. The MS delay time before scanning was $5 \mathrm{~min}$. The identification of the extract components was performed by comparing each compound's mass spectra with records in the National Institute of Standards and Technology (Gaithersburg, MD, USA) 14 and Wiley (Hoboken, NJ, USA) MS libraries.

Determination of total phenolic content. The total phenolic content (TPC) of the extracts was evaluated using the Folin-Ciocâlteu technique as described by Shahidi and Zhong, with a few modifications. Briefly, $100 \mu \mathrm{L}(0.5 \mathrm{mg} / \mathrm{mL})$ of the OGE, OGM, and OGW extracts was placed in separate tubes. Next, $500 \mu \mathrm{L}(1 \% \mathrm{v} / \mathrm{v})$ of Folin-Ciocâlteu reagent was added to each tube and the tubes were gently agitated for $5 \mathrm{~min}$. Subsequently, $400 \mu \mathrm{L}(20 \% \mathrm{w} / \mathrm{w})$ of sodium carbonate was added to the aliquots, which were then incubated in the dark at room temperature for $20 \mathrm{~min}$. The absorbance of each mixture was evaluated with an ultraviolet-visible spectrophotometer at $765 \mathrm{~nm}$. Sodium carbonate solution without any addition of Folin-Ciocâlteu reagent were used as blanks. For the calibration curve, gallic acid standards were used. TPCs of the samples were determined from the linear regression of the gallic acid standards. The results were represented as the gallic acid equivalent (GAE) per gram of dry weight of $O$. gratissimum extract (mg GAE/g). The procedure was conducted in triplicate $(n=3)$.

DPPH free radical scavenging assay. The free radical scavenging activity of each extract was determined according to the methods described by Rakmai et al. ${ }^{12}$, with slight modifications. In brief, $2 \mathrm{~mL}$ of DPPHmethanol solution $(180 \mu \mathrm{mol} / \mathrm{L})$ was mixed with the different extracts $(0.1 \mathrm{mg} / \mathrm{mL})$. The aliquots were incubated in the dark at $25^{\circ} \mathrm{C}$. The absorbance of each sample was determined using a spectrophotometer at $517 \mathrm{~nm}$ at different time intervals (0-60 min). Aliquots of the extracts without addition of DPPH-methanol solution were used as blanks. Trolox, a synthetic analog of vitamin E, was used as a positive control. Equation (1) was used to evaluate the scavenging properties of the extracts. The procedure was carried out in triplicate $(\mathrm{n}=3)$

$$
\% \mathrm{DPPH}_{\text {scavenging }}=\left[\frac{\left(\mathrm{A}_{\text {extract }}-\mathrm{A}_{\text {blank }}\right)}{\left.\mathrm{A}_{\text {control }}\right)} \times 100\right]
$$

where $A_{\text {sample }}$ is the extract + DPPH, $A_{\text {blank }}$ is the extract only, $A_{\text {control }}$ is the absorbance of the control solution (containing only DPPH).

Mathematical modeling of antioxidant activity. To generate a description of the process, some assumptions were made, including:

(1) The particles are solid, with a uniform distribution of bioactive components within the sphere.

(2) Absolute miscibility of solvent, with negligible liquid phase transfer resistance. 
(3) The migrations of bioactive components in plant samples are according to the coefficient of diffusion (Cd) and independent of time.

(4) The bioactivity of the plant chemical constituent in the solvent is time-dependent.

To determine the antioxidant kinetic pattern of the O. gratissimum extracts, the general kinetic models of zero-, first-, and second-order reactions were adopted, as presented in Eqs. (2)-(4), respectively ${ }^{13}$

$$
\begin{gathered}
{\left[C_{0}\right]-[C]=k t} \\
{[C]=\left[C_{0}\right] \exp (-\mathrm{kt})} \\
\frac{1}{[C]}-\frac{1}{\left[C_{0}\right]}=k t
\end{gathered}
$$

where $t$ is the reaction time (day); $k$ (/day) represents the reaction constant; $\left[C_{0}\right]$ and $[C]$ are the initial and final amounts of compounds, respectively, at the different times $t$ and temperatures $\left({ }^{\circ} \mathrm{C}\right)$.

Calculation of phenolic content coefficient and relative antioxidant activity index. The relative antioxidant capacity (RACI) was calculated to further compare the antioxidant activity of the different extracts according to methods by Gorjanovic et al. ${ }^{14}$. RACI was calculated by subtracting the antioxidant mean values of the extracts from the raw data divided by the standard deviation. The formula for calculating the RACI is presented in Eq. (5)

$$
\mathrm{RACI}=\frac{\mathrm{y}-\mathrm{x}}{\sigma}
$$

where $\sigma$ represents the standard deviation, $y$ raw data, and $x$ the mean. The phenolic antioxidant coefficient (PAC) were calculated as the ratio between the total phenolic content and the antioxidant capacity of the extracts ${ }^{15}$.

Evaluation of antibacterial activity of O. gratissimum extracts. Two strains of Gram-negative bacteria, S. typhimurium (ATCC 13311) and E. coli (ATCC 8739), and two strains of Gram-positive bacteria, $B$. cereus (ATCC I4579) and S. aureus (ATCC 25923), were obtained in suspension from the American Type Culture Collection (Manassas, VA, USA). All were adjusted to $1.5 \times 10^{8} \mathrm{CFU} / \mathrm{mL}$ which is the McFarland standard, and examined to discern their minimum inhibitory concentration (MIC) and minimum bactericidal concentration (MBC) relative to OGE, OGM, and OGW extracts using the microdilution method described by Devrnja et al. ${ }^{16}$, with some modifications. Briefly, extracts were diluted to concentrations of $500-2 \mathrm{mg} / \mathrm{mL}$ and added to the micro-well plates containing MHB. Next, $10 \mu \mathrm{L}$ of the McFarland standardized microbial suspension inoculums were added to all of the wells for each type of bacteria strain, and the plates were then incubated for $24 \mathrm{~h}$ at $37^{\circ} \mathrm{C}$. The MIC of the samples were established following the addition of $40 \mu \mathrm{L}$ of iodonitrotetrazolium chloride (INT; $0.02 \% \mathrm{~m} / \mathrm{v}$ ) and incubation for $30 \mathrm{~min}$ at $37^{\circ} \mathrm{C}$. The lowest concentration having no form of microbial growth $(P \leq 0.005)$ in comparison with the positive control (culture medium containing Tween 80 , microbial suspension, and ethanol) was established as the MIC. Culture medium (MHB) containing only the different types of bacteria strain served as the negative control. To further establish the MIC, the bacteria in the culture medium showing no microbial growth were transferred to an MHA plate and then incubated at $37^{\circ} \mathrm{C}$ for $24 \mathrm{~h}$. The lowest concentrations of the O. gratissimum extracts (OGE, OGM, and OGW) that inhibited the proliferation of the test microorganism after $24 \mathrm{~h}$ of incubation at $37^{\circ} \mathrm{C}$ were reported as the respective MBCs. All experimental procedures were conducted in triplicate $(n=3)$.

Trypan blue exclusion assay. The determination of the cytotoxic properties of $O$. gratissimum extracts on MDA-MB-231 cells was carried out using a trypan blue dye exclusion assay. Cells $\left(3 \times 10^{4} / \mathrm{mL}\right)$ were plated in $35 \mathrm{~mm}$ dishes and allowed to incubate overnight before treatment with several concentrations of extract $(0-100 \mu \mathrm{g} / \mathrm{mL})$ according to the respective OGE-40, OGE-50, OGE-60, OGM-40, OGM-50, OGM-60, OGW90, OGW-100, and OGW-110 protocols. The control group was treated with $1 \mathrm{~mL}$ of Dulbecco's modified eagle medium. After a 48-h incubation period, trypan blue dye (4\%) was dropped into all culture plates, which were further incubation for $40 \mathrm{~min}$. The viability of the cells was determined using an inverted microscope (DFC295; Leica Camera, Wetzlar, Germany), choosing cells from 30 randomly selected sites within the dishes.

Statistical analyses. All experiments were conducted a minimum of three times $(\mathrm{n} \geq 3)$. One-way analysis of variance (ANOVA) and Student's two-tailed $t$ test were used for statistical comparisons. Differences in mean values were regarded as very significant at $P \leq 0.0001$, significant at $P \leq 0.05$, and nonsignificant at $P>0.05$. The Statistical Package for the Social Sciences version 23 software program (IBM Corporation, Armonk, NY, USA) was used to perform statistical analysis and computations. The OriginPro version 2016 software program (OriginLab Corporation, Northampton, MA, USA) was used to create graphical representations of results.

\section{Results and discussion}

Gas chromatographic chemical composition analysis of 0 . gratissimum extracts. The extraction procedure is one of the most important steps in the use of natural resources, as it can affect the chemical makeup as well as the biological properties of extracts obtained. Several methods of extraction rely on different 


\begin{tabular}{|l|l|l|l|l|}
\hline \multirow{2}{*}{ Retention time $(\mathbf{m i n})$} & & \multicolumn{3}{|l|}{ Content $(\%, w t / w t)$} \\
\cline { 3 - 5 } & Chemical name & OGE-40 & OGE-50 & OGE-60 \\
\hline 15.692 & Sabinene & 0.48 & 0.51 & 0.74 \\
\hline 19.858 & $\gamma$-Terpinene & 4.61 & 3.21 & 5.02 \\
\hline 33.017 & Thymol & 2.17 & 1.07 & 2.23 \\
\hline 35.7 & $\alpha$-copaene & 0.53 & 0.93 & 1.47 \\
\hline 37.575 & Trans-caryophyllene & 1.51 & 1.12 & 1.96 \\
\hline 39.2 & a-Humulene & 0.88 & 1.28 & 0.54 \\
\hline 40.233 & $\beta$-Selinene & 4.41 & 3.65 & 4.89 \\
\hline 44.65 & Caryophyllene oxide & 2.01 & 1.67 & 2.28 \\
\hline 55.183 & Trans-phytol & 0.19 & 0.19 & 0.19 \\
\hline
\end{tabular}

Table 1. Chemical composition of O. gratissimum ethanolic extract.

\begin{tabular}{|l|l|l|l|l|}
\hline \multirow{2}{*}{ Retention time (min) } & & \multicolumn{3}{l|}{ Content (\%, wt/wt) } \\
\cline { 3 - 5 } & Chemical name & OGM-40 & OGM-50 & OGM-60 \\
\hline 5.092 & Methyl ester & 0.04 & 0.15 & 0.18 \\
\hline 5.742 & Glycerin & 0.45 & 0.52 & 0.45 \\
\hline 18.142 & Cymene & 4.66 & 4.68 & 4.65 \\
\hline 32.275 & Thymol & 0.13 & 0.16 & 0.24 \\
\hline 37.917 & Trans-caryophyllene & 0.39 & 1.34 & 0.42 \\
\hline 40.975 & 3-Selinene & 0.29 & 0.31 & 0.96 \\
\hline 42.092 & Phenol, 3-(1,1-dimethylethyl)-4-methoxy- & 0.70 & 0.85 & 0.87 \\
\hline 55.4 & Phytol & 0.51 & 1.21 & 0.43 \\
\hline 56.033 & Trans-phytol & 0.96 & 0.92 & 1.12 \\
\hline 60.425 & Phenol, 2-methyl-5-(1-methylethyl)-(CAS) carvacrol & 0.85 & 0.52 & 0.89 \\
\hline
\end{tabular}

Table 2. Chemical profiling for methanolic extract of O. gratissimum.

analyte mechanisms of isolation from matrices, and the technique used may rely on the nature of the plant material. For this study, the chemical profiles of three different extracts (OGE, OGM, and OGW) were revealed using GC-MS. The results obtained for the OGE are presented in Table 1, which shows that the lowest concentration (\% wt/wt) of observed components was found in extracts prepared at $50{ }^{\circ} \mathrm{C}(\mathrm{OGE}-50)$, while the concentrations were higher in extracts prepared at $40^{\circ} \mathrm{C}(\mathrm{OGE}-40)$ and at $60^{\circ} \mathrm{C}$ (OGE-60). Samples obtained using ethanolic and methanolic extracts contained a higher amount of bioactive compounds, including sabinene, terpenene, thymol, copaene, caryophyllene, humulene, selinene, caryphylene oxides, and phytol, compared to OGW extracts. The concentration of constituent compounds in OGE extracts varies at different temperatures, with OGE-60 > OGE-40 > OGE-50. This might be due to altered dissolving abilities of the solvents at different temperatures during the process of extraction ${ }^{17}$. A study by Cvetanović et al. ${ }^{18}$ on extractions of Aronia melanocarpa $\mathrm{M}$. stem reported more flavonoids and phenolic content in extractions with ethanol compared to extractions with methanol. In contrast, our results revealed that a high number of compounds was observed in OGM extracts in all cases (Table 2). Hence, it can be generalized that extraction with methanol is the preferred technique for isolation of several bioactive compounds from the O. gratissimum plant. As reported by Gharaati ${ }^{19}$, methanol can easily infiltrate into plant tissue and increase the process of extraction. The concentration of compounds in the methanolic extracts was highest in OGM-40, followed by OGM-60 and OGM-50. For OGW extracts, those prepared at $110^{\circ} \mathrm{C}$ showed the highest number and concentration of identified compounds, as reported in Table 3 . The differences in concentration of compounds could be a consequence of the extraction temperature resulting in rupture of the plant cell walls, leading to diffusion of the plant constituents into the water medium. Moreover, the lower number of bioactive compounds in OGW extracts compared to OGE and OGM extracts might be due to reduced compound solubility in water, as well as the extraction conditions. Nevertheless, an increase in temperature causes a decrease in water's dielectric constant, and as a result, fewer polar compounds will be dissolved in it. Chemical and physical properties of water can change drastically under supercritical conditions. In addition, under certain operational conditions, the polarity of water can be fine-tuned ${ }^{18}$.

Total phenolic content of O. gratissimum extracts. TPC yield is essential, especially for industrial applications at large scale and for economic purposes. Thus, this study aimed to identify the extraction technique generating the highest TPC yield. Phenolic profiling of extracts was established by applying the Folin-Ciocâlteu method (Table 4). Significant differences $(P<0.05)$ in TPC were observed for the extractions obtained using the different methods. The amount of TPC obtained in OGM-40 (2.43 $\pm 0.24 \mathrm{mg}$ GAE/100 g) was approximately 


\begin{tabular}{|l|l|l|l|l|}
\hline & & \multicolumn{3}{l|}{ Content $(\%, w t / w t)$} \\
\cline { 3 - 5 } Retention time $(\mathbf{m i n})$ & Chemical name & OGW-90 & OGW-100 & OGW-110 \\
\hline 5.075 & 1,2-Butanediol & 0.09 & 0.07 & 0.12 \\
\hline 28.825 & N-Acetyl-proline & 4.40 & 2.92 & 4.85 \\
\hline 32.425 & Phenol, 5-methyl-2-(1-methylethyl) & 2.53 & 1.41 & 3.06 \\
\hline 37.867 & Caryophyllene & 0.29 & 0.13 & 0.41 \\
\hline 40.892 & -Selinene & 0.72 & 0.64 & 0.94 \\
\hline 44.975 & Caryophyllene oxide & 4.31 & 3.31 & 4.86 \\
\hline 54.367 & Neophytadiene & 4.39 & 4.39 & 4.39 \\
\hline 55.9 & 2-Hexadecen-1-ol, 3,7,11,15-tetramethyl-, $\left[\mathrm{R}_{-}-\left[\mathrm{R}^{*}, \mathrm{R}^{*}-(\mathrm{E})\right]\right]$ & 4.38 & 1.38 & 4.26 \\
\hline
\end{tabular}

Table 3. Chemical composition of O. gratissimum water extract.

\begin{tabular}{|l|l|}
\hline Extracts & TPC $(\mathbf{m g ~ G A E} / \mathbf{1 0 0} \mathbf{g})$ \\
\hline OGE-40 & $1.38 \pm 0.26^{\mathrm{a}}$ \\
\hline OGE-50 & $1.36 \pm 0.32^{\mathrm{a}}$ \\
\hline OGE-60 & $2.29 \pm 0.31^{\mathrm{b}}$ \\
\hline OGM-40 & $2.43 \pm 0.24^{\mathrm{c}}$ \\
\hline OGM-50 & $1.41 \pm 0.21^{\mathrm{a}}$ \\
\hline OGM-60 & $1.82 \pm 0.74^{\mathrm{c}}$ \\
\hline OGW-90 & $1.26 \pm 0.44^{\mathrm{a}}$ \\
\hline OGW-100 & $1.15 \pm 0.52^{\mathrm{d}}$ \\
\hline OGW-110 & $1.80 \pm 0.61^{\mathrm{c}}$ \\
\hline
\end{tabular}

Table 4. Content of phenolics from different O. gratissimum extracts. Values shown are mean of three replicates $(n=3) \pm S D$. Values with different superscript lowercase letter $(a-d)$ within each column are significantly different $(P \leq 0.05)$.

$50 \%$ higher than the corresponding value obtained from the rest of the extracts, while this value was much lower in the case of OGW-100. At a temperature of $110^{\circ} \mathrm{C}$, however, OGW exhibited much higher $(P<0.05)$ TPC yields than OGE-40, OGE-50, and OGM-50. Similar findings were reported by Fan et al. ${ }^{20}$. OGM-40 showed the highest yield of phenolic content and is hence considered to be the most effective phenolic extraction technique for O. gratissimum. This could be due to the high polarity and subcritical dissociation of bonds of methanol compared to other types of solvent during phenolics recovery from this plant. With regards to the different extraction techniques, our findings are in line with those of the study by Veličković et al. ${ }^{21}$. The O. gratissimum phenolic content has been well established in the literature; however, several factors, such as harvest season, type of fertilization, habitat/location, and plant malnutrition, can affect the phenolic content in O. gratissimum ${ }^{22}$. Literature data suggest that $O$. gratissimum contains high levels of polyphenols, flavonoids, and fatty acids ${ }^{23,24}$. To our knowledge, this study is the first to report a comprehensive analysis of the effect of temperature and solvent type on the TPC of O. gratissimum.

Antioxidant activities of 0 . gratissimum extracts. In a biological system, free radicals can cause damage in vivo and are consequently considered a cause of numerous diseases. Hence, the scavenging of free radicals is an essential task for antioxidant compounds to protect living systems. The results of our experiments testing antioxidant activity revealed that the extracts investigated showed notable potential for oxidation inhibition. As shown in Fig. 1, the activity can be ranked as follows: OGM-40> OGE-60 > OGW-110 > OGM$50>$ OGE-40 > OGE-50 > OGW-90>OGW-100. The free radical-scavenging activity of compounds, as outlined by Kfoury et al. ${ }^{24}$, is examined after 30 min contact of DPPH solution with the compound. However, Kamimura et al. ${ }^{25}$ proposed that the antioxidant activity of compounds is likely to last much longer, depending on the oxidation kinetics over time. OGM antioxidant ability was higher from the period of $1-5 \mathrm{~h}$ compared to the rest of the extracts. The high antioxidant activity of OGM-40 is attributed to the high level of phenolics in this extract compared to the others. The findings of this study are in agreement with those of the study by Ngo et al. ${ }^{26}$ on antioxidant activity of methanolic extracts of Salacia chinensis L. root.

Among the $\mathrm{OGW}$ extracts, the scavenging power was the greatest at $100{ }^{\circ} \mathrm{C}$, less at $90{ }^{\circ} \mathrm{C}$, and even more reduced at $110^{\circ} \mathrm{C}$. This shows that antioxidant properties can be greatly reduced at extraction temperatures above the optimum/boiling temperature of the solvent, as this can lead to the denaturation of phenolics, as was the case with OGW-110.

For the OGE and OGM extracts, the effect of temperature on the oxidant-scavenging properties of these extracts was in line with the findings of Molaveisi, Beigbabaei, Akbari, Noghabi, and Mohamadi ${ }^{27}$. 


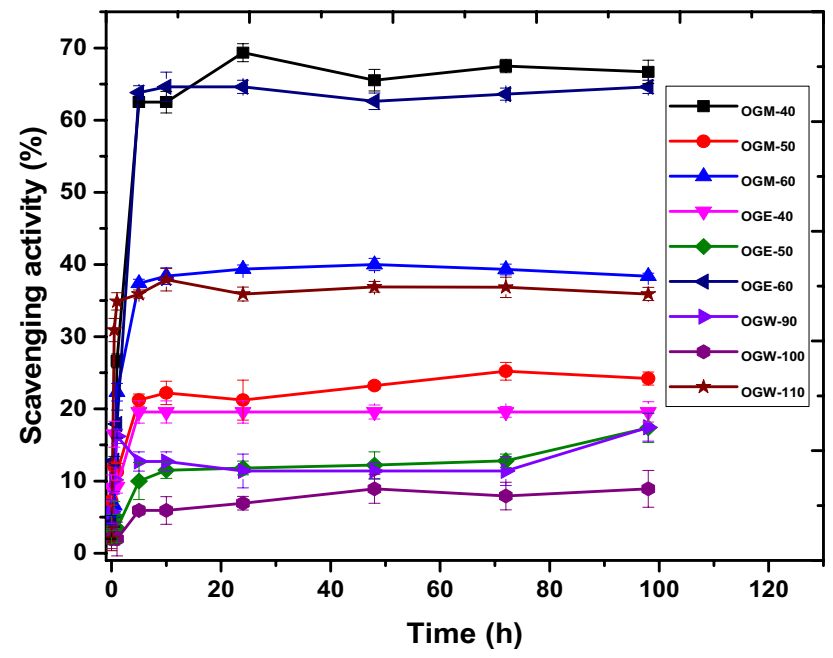

Figure 1. Antioxidant activity of O. gratissimum extract (results are mean values of three replicates [ $\mathrm{n}=3$ ] expressed in percentage; bars represent standard deviations).

\begin{tabular}{|l|l|}
\hline Extracts & Scavenging activity $\left(\mathbf{I C}_{\mathbf{5 0}} ; \mathbf{m g} / \mathbf{m L}\right)$ \\
\hline OGE-40 & $0.55 \pm 0.10^{\mathrm{a}}$ \\
\hline OGE-50 & $0.72 \pm 0.11^{\mathrm{b}}$ \\
\hline OGE-60 & $0.83 \pm 0.01^{\mathrm{c}}$ \\
\hline OGM-40 & $1.76 \pm 0.01^{\mathrm{b}}$ \\
\hline OGM-50 & $1.14 \pm 0.41^{\mathrm{c}}$ \\
\hline OGM-60 & $1.84 \pm 0.02^{\mathrm{b}}$ \\
\hline OGW-90 & $0.81 \pm 0.08^{\mathrm{b}}$ \\
\hline OGW-100 & $1.86 \pm 0.03^{\mathrm{b}}$ \\
\hline OGW-110 & $1.95 \pm 0.09^{\mathrm{b}}$ \\
\hline
\end{tabular}

Table 5. Half-maximal concentration $\left(\mathrm{IC}_{50}\right)$ values for the $\mathrm{DPPH}$ free radical-scavenging activity assay of $O$. gratissimum extracts. Values shown are means of three replicates $(n=3) \pm S D$. Values with different superscript letters $(\mathrm{a}-\mathrm{c})$ within each column are significantly different $(P \leq 0.05)$.

The DPPH scavenging capacity of the extracts was also evaluated by calculating their $\mathrm{IC}_{50}$ values, which correlates to the amount of extract that is capable of scavenging $50 \%$ of the free radicals contained in the reaction mixture. A low $\mathrm{IC}_{50}$ value indicates high free radical-scavenging activity, and vice versa. The $\mathrm{IC}_{50}$ values of the extracts are within the range of $0.75-2.84 \mathrm{mg} / \mathrm{mL}$ (Table 5). Based on the $\mathrm{IC}_{50}$ values, the order of free radicalscavenging activity of the extracts is as follows: OGE-40> OGE-50> OGE-60 > OGW-90 > OGM-50 $>$ OGM$40>$ OGM-60 > OGW-100 > OGW-110 (Table 5). The high antioxidant capacity of O. gratissimum is often considered a function of its high phenolic content. However, our results showed that extracts with low TPC also exhibited high antioxidant activity, suggesting that in addition to phenolics, other factors, such as extraction temperature and solvent type, can also contribute to an extract's antioxidant activity.

Phenolic antioxidant coefficient and relative capacity index. In order to further compare the TPC and antioxidant capacity of the extracts, two additional parameters, namely, PAC, which is the ratio between TPC, and particular antioxidant capacity; and RACI, which determines the total reducing capacity, were introduced. In Fig. 2, it can be seen that the highest RACI value is ascribed to OGE-40 (1.26), followed by OGE-50 (0.34). Negative RACI values were seen for OGM-40 (-2.25), OGM-50 (-0.30), OGM-60 (-4.26), OGE-60 $(-1.30)$, OGW-90 (-0.73), OGW-100 (-1.31), and OGW-110 (-0.94). Though RACI and TPC show the antioxidant capacity of phenolics to a certain extent, PAC compares the efficiencies of phenolic in the samples. Interestingly, the lowest PAC values are seen for extracts with positive RACI values (i.e., high antioxidant capacity), while extracts with the most-negative RACI values possess higher PAC values (Fig. 2). A study by Wojdylo et al. ${ }^{28}$ suggest that with high PAC values are not a reflection of high antioxidant activity in plants; however, plants with substantial PAC and RACI values is an indication of their rich antioxidant potential. The findings of this study are similar to those from a study by Petrovic et al..$^{29}$. 

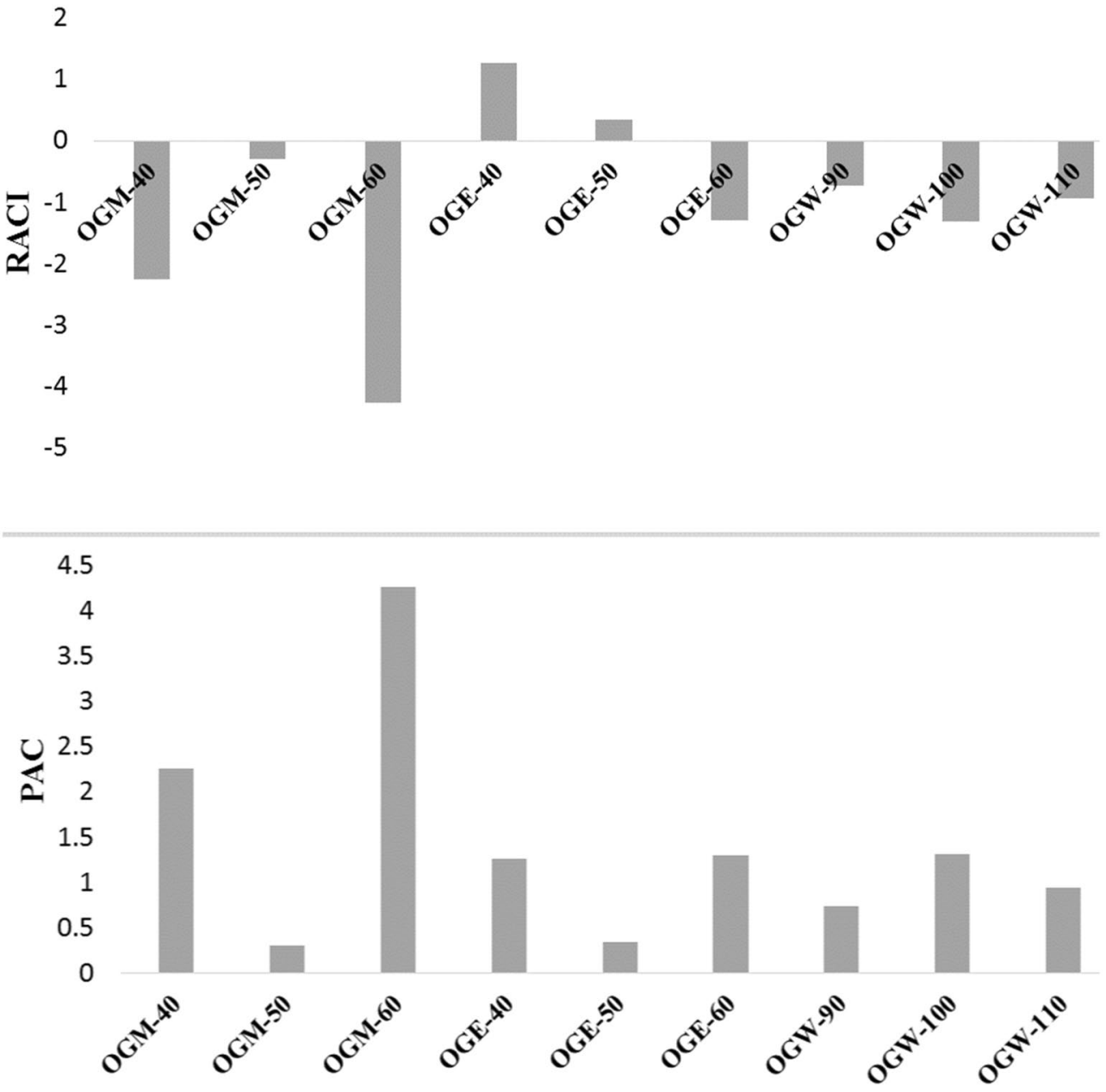

Plant extracts

Figure 2. Phenolic antioxidant coefficient (PAC) and relative antioxidant capacity index (RACI) of $O$. gratissimum extracts.

Kinetic models for the study of the effect of solvent composition and temperature on the antioxidant activity of 0 . gratissimum extracts. As shown in Fig. 3, varying the temperature and type of solvent had a significant effect on the antioxidant kinetics of $O$. gratissimum extracts. Data analysis using several kinetic models showed that the highest coefficient of determination $\left(\mathrm{r}^{2}\right)$ value for both the zero- and first-order kinetic models was achieved with OGE-50, with $\mathrm{r}^{2}$ values of 0.694 and 0.793 , respectively. In contrast, for the second-order model, the highest adjusted $\mathrm{r}^{2}$ value was achieved with OGE- $60\left(\mathrm{r}^{2}=0.436, \mathrm{~K}=0.314\right.$; Table 6$)$. The linear relationship between $\ln \mathrm{K}$ for the antioxidant activity for all the extracts over time had the best fit to the second-order kinetics model. These results are in agreement with previous studies, such as a study that reported the kinetics of the effect of temperature on antioxidant activity of Iranian jujube hone ${ }^{27}$. The kinetic parameter rate constant $(\mathrm{K})$ for the antioxidant activity of $\mathrm{O}$. gratissimum showed a strong temperature dependence for the second-order model, as $\mathrm{K}$ tends to increase with an increase in temperature. For example, OGW at the temperatures of $90^{\circ} \mathrm{C}, 100^{\circ} \mathrm{C}$, and $110^{\circ} \mathrm{C}$ had $\mathrm{K}$ values of $0.081,0.084$, and 0.246 , respectively. This result indicates that extractions at higher temperatures lead to a faster decrease in antioxidant activity. Similar results were observed for ascorbic acid in ground cashew apple ${ }^{30}$ and anthocyanins in blackberry juice and its concentrate ${ }^{31}$.

Antibacterial activity of 0 . gratissimum extracts. The MIC and MBC measured for each extract are presented in Table 7. For each extract, the MIC was within the $5-150 \mu \mathrm{g} / \mathrm{mL}$ range, which, according to a study by Kavaz et al. ${ }^{5}$, indicates very good antibacterial activity. The highest sensitivity to $O$. gratissimum extract was demonstrated by $S$. aureus, while S. typhimurium was the most resistant. A significant difference $(P<0.05)$ in antimicrobial activity was observed for all of the extracts when compared to the negative control. The OGM-40 extract had a significantly higher antibacterial activity for all bacteria tested compared to the rest of the extracts. For S. aureus, particularly high antibacterial activity was observed, as the MIC value was $5 \mu \mathrm{g} / \mathrm{mL}$. The rest of the bacteria strains also showed high sensitivity to OGM extracts. For OGE-40, the lowest MBC was against $B$. cereus $(150 \mu \mathrm{g} / \mathrm{mL})$. OGE-50, OGW-90, and OGW-100 had the same MBC values for all bacteria $(250 \mu \mathrm{g} / \mathrm{mL}$, 

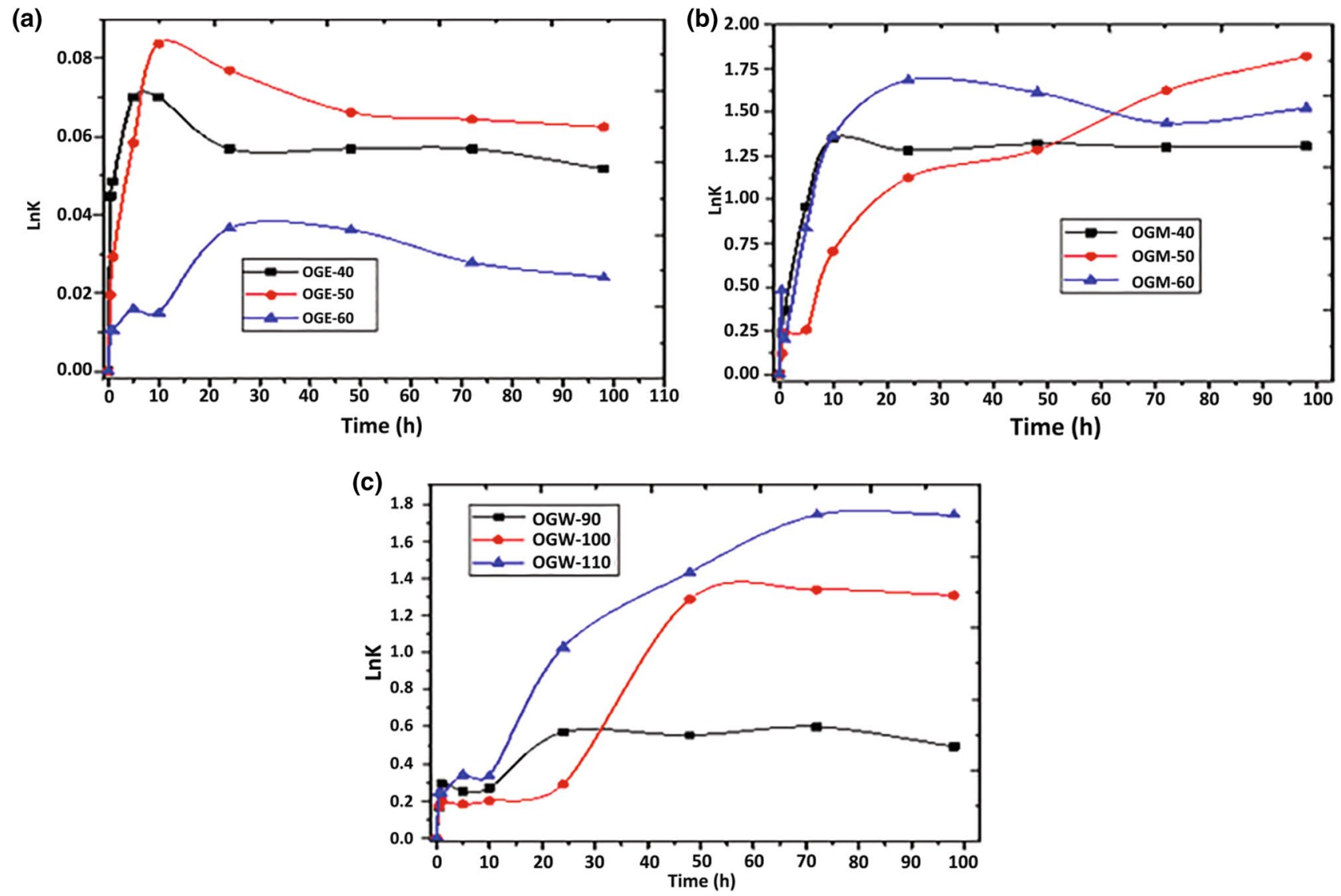

Figure 3. Arrhenius plots for the DPPH radical-scavenging activity of $O$. gratissimum extracts at different extraction temperatures as a function of exposure time. (a) Ethanolic extracts, (b) methanolic extracts, (c) water extracts. Bars represent mean \pm standard deviation.

\begin{tabular}{|l|l|l|l|l|l|l|}
\hline \multirow{2}{*}{ Sample } & \multicolumn{2}{|l|}{ Zero order } & \multicolumn{2}{l|}{ First order } & \multicolumn{2}{l|}{ Second order } \\
\cline { 2 - 8 } & $\mathbf{r}^{\mathbf{2}}$ & $\mathbf{K}_{\mathbf{0}}$ & $\mathbf{r}^{\mathbf{2}}$ & $\mathbf{K}_{\mathbf{1}}$ & $\mathbf{r}^{\mathbf{2}}$ & $\mathbf{K}_{\mathbf{2}}$ \\
\hline OGM-40 & 0.378 & 0.005 & 0.032 & 0.001 & 0.242 & 0.019 \\
\hline OGM-50 & 0.270 & 0.001 & 0.431 & 0.001 & 0.2387 & 0.034 \\
\hline OGM-60 & 0.494 & 0.001 & 0.453 & 0.001 & 0.202 & 0.084 \\
\hline OGE-40 & 0.192 & 0.001 & 0.189 & 0.001 & 0.148 & 0.037 \\
\hline OGE-50 & 0.694 & 0.001 & 0.793 & 0.001 & 0.409 & 0.17 \\
\hline OGE-60 & 0.657 & 0.001 & 0.083 & 0.001 & 0.436 & 0.314 \\
\hline OGW-90 & 0.325 & 0.002 & 0.090 & 0.06 & 0.237 & 0.081 \\
\hline OGW-100 & 0.339 & 0.004 & 0.433 & 0.001 & 0.202 & 0.084 \\
\hline OGW-110 & 0.259 & 0.002 & 0.320 & 0.001 & 0.203 & 0.246 \\
\hline
\end{tabular}

Table 6. Kinetic parameters of DPPH radical-scavenging activity of O. gratissimum extracted with different solvents at different temperatures as a function of exposure time. $r^{2}$ regression coefficient, $K_{0}$ rate constant for zero-order reaction, $K_{1}$ rate constant for first-order reaction, $K_{2}$ rate constant for second-order reaction.

$250 \mu \mathrm{g} / \mathrm{mL}$, and $300 \mu \mathrm{g} / \mathrm{mL}$, respectively), while the highest antibacterial activity for OGM-60 was against $E$. coli and $B$. cereus $(100 \mu \mathrm{g} / \mathrm{mL})$. In addition, for OGE-60, the highest antibacterial activity was observed for $S$. aureus $(40 \mu \mathrm{g} / \mathrm{mL})$, and for OGM-50 and OGW-100, the highest antibacterial activity was against $B$. cereus, at $100 \mu \mathrm{g} / \mathrm{mL}$ and $80 \mu \mathrm{g} / \mathrm{mL}$, respectively. Although the OGW samples showed the lowest antibacterial properties, they still showed antimicrobial activity at higher concentrations. In general, antimicrobial activity of the different extracts of $O$. gratissimum may be related to the phytochemical composition ${ }^{5}$, extraction techniques, and multiple mechanisms of action ${ }^{32}$.

Cytotoxic activity assay. Exclusion assay with trypan blue dye revealed high toxicity of $O$. gratissimum on MDA-MB-231, a highly metastatic breast cancer cell line, after treatment with the extracts for a period of $48 \mathrm{~h}$ 


\begin{tabular}{|c|c|c|c|c|c|c|c|c|}
\hline \multirow[b]{2}{*}{$\begin{array}{l}\text { Antibacterial } \\
\text { compound }\end{array}$} & \multicolumn{2}{|l|}{ E. coli } & \multicolumn{2}{|l|}{ B. cereus } & \multicolumn{2}{|l|}{ S. aureus } & \multicolumn{2}{|c|}{ S. typhimurium } \\
\hline & $\operatorname{MIC}(\mu \mathrm{g} / \mathrm{mL})$ & $\begin{array}{l}\mathrm{MBC}(\mu \mathrm{g} / \\
\mathrm{mL})\end{array}$ & $\begin{array}{l}\mathrm{MIC}(\mu \mathrm{g} / \\
\mathrm{mL})\end{array}$ & $\begin{array}{l}\mathrm{MBC}(\mu \mathrm{g} / \\
\mathrm{mL})\end{array}$ & $\begin{array}{l}\text { MIC }(\mu \mathrm{g} / \\
\mathrm{mL})\end{array}$ & $\begin{array}{l}\mathrm{MBC}(\mu \mathrm{g} / \\
\mathrm{mL})\end{array}$ & $\begin{array}{l}\mathrm{MIC}(\mu \mathrm{g} / \\
\mathrm{mL})\end{array}$ & $\operatorname{MBC}(\mu \mathrm{g} / \mathrm{mL})$ \\
\hline OGE-40 & $100 \pm 5.06^{\mathrm{aA}}$ & $200 \pm 9.69^{\mathrm{aB}}$ & $100 \pm 10.4^{\mathrm{aA}}$ & $150 \pm 7.54^{\mathrm{aC}}$ & $150 \pm 5.31^{\mathrm{aC}}$ & $200 \pm 7.84^{\mathrm{aB}}$ & $250 \pm 4.32^{\mathrm{aD}}$ & $300 \pm 8.36^{\mathrm{aE}}$ \\
\hline OGE-50 & $140 \pm 8.43^{\mathrm{bA}}$ & $250 \pm 7.83^{\text {bB }}$ & $140 \pm 6.84^{\mathrm{bA}}$ & $250 \pm 5.62^{\mathrm{bB}}$ & $140 \pm 7.64^{\mathrm{aA}}$ & $250 \pm 10.32^{\mathrm{bB}}$ & $140 \pm 9.34^{\mathrm{bA}}$ & $250 \pm 9.71^{\mathrm{bB}}$ \\
\hline OGE-60 & $20 \pm 2.89^{\mathrm{cD}}$ & $60 \pm 5.5^{\mathrm{cB}}$ & $40 \pm 5.67^{\mathrm{cC}}$ & $60 \pm 6.45^{\mathrm{cB}}$ & $20 \pm 2.73^{\mathrm{bD}}$ & $40 \pm 4.67^{\mathrm{cC}}$ & $60 \pm 5.82^{\mathrm{cB}}$ & $100 \pm 9.54^{\mathrm{cA}}$ \\
\hline OGM-40 & $20 \pm 2.65^{\mathrm{cA}}$ & $40 \pm 9.21 \mathrm{~dB}$ & $10 \pm 1.65^{\mathrm{dC}}$ & $20 \pm 2.51^{\mathrm{dA}}$ & $5 \pm 0.56^{\mathrm{cD}}$ & $20 \pm 3.21^{\mathrm{dA}}$ & $40 \pm 4.84^{\mathrm{dB}}$ & $80 \pm 9.64^{\mathrm{dE}}$ \\
\hline OGM-50 & $100 \pm 6.52^{\mathrm{aE}}$ & $150 \pm 5.67^{\mathrm{eC}}$ & $80 \pm 5.4^{\mathrm{eD}}$ & $100 \pm 6.46^{\mathrm{eE}}$ & $80 \pm 6.94^{\mathrm{dD}}$ & $140 \pm 7.69^{\mathrm{eC}}$ & $200 \pm 4.75^{\mathrm{eB}}$ & $300 \pm 8.57^{\mathrm{aA}}$ \\
\hline OGM-60 & $60 \pm 3.56^{\mathrm{dA}}$ & $100 \pm 6.73^{\mathrm{fB}}$ & $60 \pm 4.56^{\mathrm{fA}}$ & $100 \pm 4.56^{\mathrm{eB}}$ & $100 \pm 7.65^{\mathrm{eB}}$ & $150 \pm 9.73^{\mathrm{fC}}$ & $100 \pm 8.53^{\mathrm{fB}}$ & $200 \pm 9.78^{\mathrm{eF}}$ \\
\hline OGW-90 & $140 \pm 4.96^{\mathrm{bC}}$ & $250 \pm 5.78^{\mathrm{bA}}$ & $140 \pm 5.65^{\mathrm{bB}}$ & $250 \pm 6.83^{\mathrm{bA}}$ & $140 \pm 7.58^{\mathrm{aC}}$ & $250 \pm 8.52^{\mathrm{bA}}$ & $140 \pm 4.78^{\mathrm{bB}}$ & $250 \pm 9.45^{\mathrm{bA}}$ \\
\hline OGW-100 & $150 \pm 8.56^{\mathrm{bA}}$ & $300 \pm 7.63^{\mathrm{gB}}$ & $150 \pm 4.65^{\mathrm{bA}}$ & $300 \pm 6.43^{\mathrm{fB}}$ & $150 \pm 6.14^{\mathrm{aA}}$ & $300 \pm 9.12^{\mathrm{gB}}$ & $150 \pm 6.14^{\mathrm{bA}}$ & $300 \pm 9.14^{\mathrm{aB}}$ \\
\hline OGW-110 & $80 \pm 5.67^{\mathrm{eC}}$ & $150 \pm 7.95^{\mathrm{eE}}$ & $40 \pm 4.41^{\mathrm{cD}}$ & $80 \pm 5.65^{\mathrm{gC}}$ & $100 \pm 5.27^{\mathrm{fC}}$ & $250 \pm 8.23^{\mathrm{bB}}$ & $150 \pm 6.43^{\mathrm{aB}}$ & $300 \pm 9.12^{\mathrm{aA}}$ \\
\hline
\end{tabular}

Table 7. Minimum inhibitory and bactericidal concentration (MIC, MBC) against E. coli, B. cereus, S. aureus, and S. typhimurium for O. gratissimum extracts. Values shown are means of three replicates $(\mathrm{n}=3)$. Values with different superscript lowercase letter $(\mathrm{a}-\mathrm{g})$ for MIC and MBC data within each column are significantly different $(P \leq 0.05)$. Values with different superscript uppercase letter $(\mathrm{A}-\mathrm{E})$ within each row are significantly different $(P \leq 0.05)$.

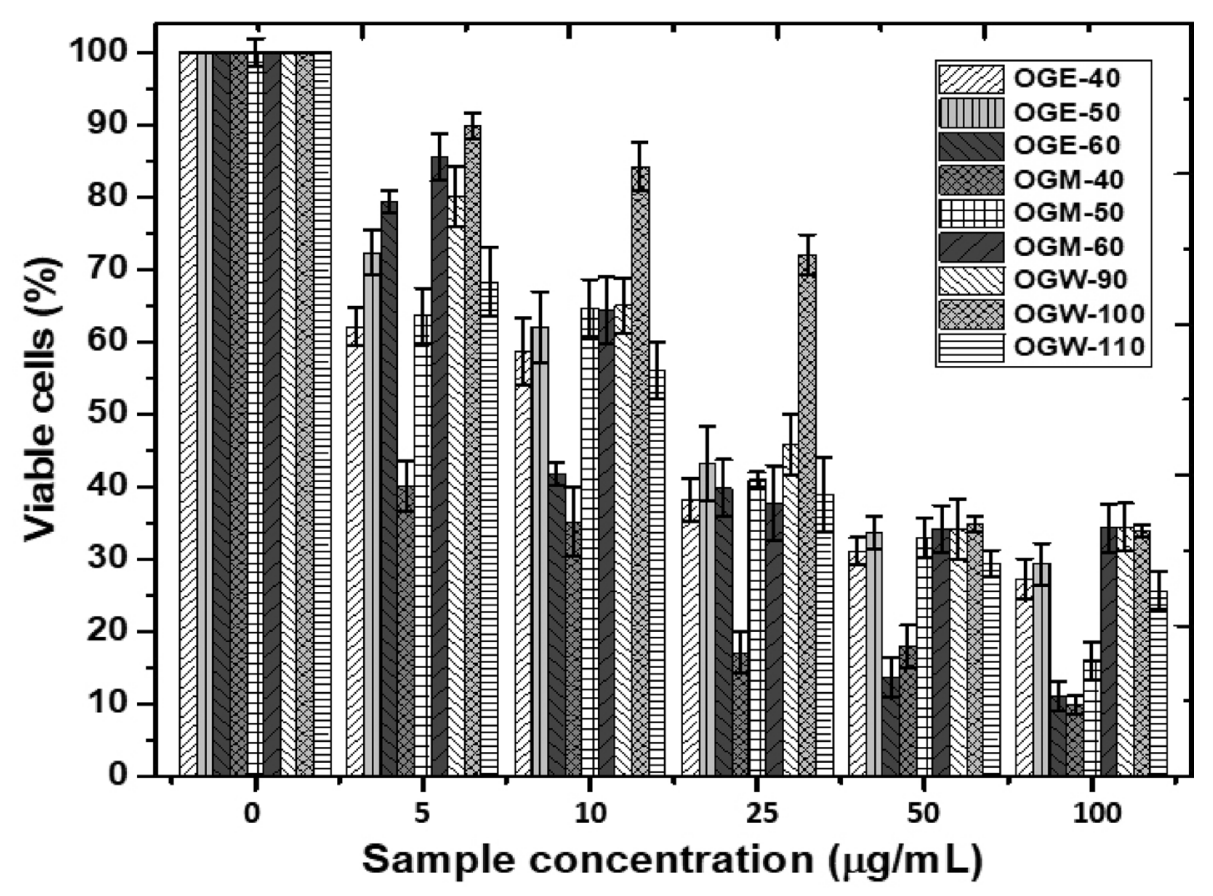

Figure 4. Effect of $48 \mathrm{~h}$ treatment with O. gratissimum extracts on MD-MD-231 breast cancer cells. Bars represent mean \pm standard deviation.

at various concentrations $(0-100 \mu \mathrm{g} / \mathrm{mL}$; Fig. 4). The results showed that cell viability declined with increases in extract concentration. The results of the experiments showed that OGM-40 inhibited the cell viability at a lower concentration compared to the rest of the extracts $(P<0.05, \mathrm{n} \geq 3$; Fig. 4$)$. The highest concentration $(100 \mu \mathrm{g} /$ $\mathrm{mL}$ ) of OGE-40, OGE-50, OGE-60, OGM-40, OGM-50, OGM-60, OGW-90, OGW-100, and OGW-11 lowered the viability of the cell line to $27.22 \%, 29.32 \%, 11 \%, 9.83 \%, 15.97 \%, 34.25 \%, 34.47 \%, 33.86 \%$, and $25.66 \%$ of the untreated control, respectively. The light microscope phase-contrast images for the trypan blue dye retention of the control group (untreated) and drug-treated cancer cells are shown in the supplementary data (Fig. S1). For the cancer cells treated with OGM-40, membrane blebs were also observed after $48 \mathrm{~h}$ of incubation. This is an indication of cell apoptosis, as suggested by Onyebuchi and Kavaz ${ }^{7}$. The high antiproliferative activity of OGM40 compared to the rest of the extracts is likely a result of oxidative stress generation within the cell membrane.

\section{Conclusion}

The chemical profile and bioactive properties of O. gratissimum extracts prepared using different extraction temperatures and solvent types were examined in this study. The results obtained herein suggest that both extraction temperature and solvent type have a significant effect on the phenolic content yield, antioxidant capacity, 
antimicrobial activity, and cancer cell cytotoxic properties of $O$. gratissimum extracts. For extracts prepared with methanol, extraction performed at $40{ }^{\circ} \mathrm{C}(\mathrm{OGM}-40)$ was the optimal protocol for obtaining high TPC and desirable chemical properties. The extracts showed strong temperature dependence and best fit with the second-order kinetic model, as the rate of antioxidant activity tends to increase with an increase in extraction temperature. The findings of this study further establish the potential use of the extracts as alternative natural food antioxidants over synthetic preservatives. The antimicrobial and anticancer properties of the extracts also demonstrate their potential applications in the pharmaceutical and food industries.

Received: 10 June 2020; Accepted: 23 November 2020

Published online: 10 December 2020

\section{References}

1. Ehling-Schulz, M., Lereclus, D. \& Koehler, T. The Bacillus cereus group: Bacillus species with pathogenic potential. Microbiol. Spect. 7, 1-60 (2019)

2. Bouarab-Chibane, L. et al. Antibacterial properties of polyphenols: Characterization and QSAR (quantitative structure-activity relationship) Models. Front. Microbiol. 10, 829 (2019).

3. Yan, Z., Zhong, Y., Duan, Y., Chen, Q. \& Li, F. Antioxidant mechanism of tea polyphenols and its impact on health benefits. Anim. Nutr. 6, 115-123 (2020).

4. Pobiega, K. et al. Growth biocontrol of foodborne pathogens and spoilage microorganisms of food by Polish propolis extracts. Molecules 24, 2965 (2019).

5. Kavaz, D., Idris, M. \& Onyebuchi, C. Physiochemical characterization, antioxidative, anticancer cells proliferation and food pathogens antibacterial activity of chitosan nanoparticles loaded with Cyperus articulatus rhizome essential oils. Int. J. Biol. Macromol. 123, 837-845 (2019).

6. Shahidi, F. \& Zhong, Y. Measurement of antioxidant activity. J. Funct. Foods. 18, 757-781 (2015).

7. Onyebuchi, C. \& Kavaz, D. Chitosan and $N, N, N$-Trimethyl chitosan nanoparticle encapsulation of Ocimum gratissimum essential oil: Optimised synthesis, in vitro release and bioactivity. Int. J. Nanomed. 14, 7707-7727 (2019).

8. Alabi, Q. et al. Polyphenol-rich extract of Ocimum gratissimum leaves ameliorates colitis via attenuating colonic mucosa injury and regulating pro-inflammatory cytokines production and oxidative stress. Biomed. Pharmacother. 103, 812-822 (2018).

9. Kumar, A. et al. Delineation of Ocimum gratissimum L. complex combining morphological, molecular and essential oils analysis. Ind. Crops Prod. 139, 111536 (2019).

10. Benelli, G. et al. Insecticidal activity of the essential oil and polar extracts from Ocimum gratissimum grown in Ivory Coast: Efficacy on insect pests and vectors and impact on non-target species. Ind. Crops Prod. 132, 377-385 (2019).

11. Méndez-Lagunas, L., Rodríguez-Ramírez, J., Cruz-Gracida, M., Sandoval-Torres, S. \& Barriada-Bernal, G. Convective drying kinetics of strawberry (Fragaria ananassa): Effects on antioxidant activity, anthocyanins and total phenolic content. Food Chem. 230, 174-181 (2017).

12. Rakmai, J., Cheirsilp, B., Mejuto, J., Torrado-Agrasar, A. \& Simal-Gándara, J. Physico-chemical characterization and evaluation of bio-efficacies of black pepper essential oil encapsulated in hydroxypropyl-beta-cyclodextrin. Food Hydrocoll. 65, 157-164 (2017).

13. Ritzoulis, C. \& Rhoades, J. Introduction to the Physical Chemistry of Foods (Taylor \& Francis, Boca Raton, 2013).

14. Gorjanović, S. et al. Comparative analysis of antioxidant activity of honey of different floral sources using recently developed polarographic and various spectrophotometric assays. J. Food Compost. Anal. 30, 13-18 (2013).

15. Gorjanović, S. et al. Antioxidant capacity of teas and herbal infusions: Polarographic assessment. J. Agric. Food Chem. 60, 9573-9580 (2012).

16. Devrnja, N. et al. Comparative studies on the antimicrobial and cytotoxic activities of Tanacetum vulgare L. essential oil and methanol extracts. S. Afr. J. Bot. 111, 212-221 (2017).

17. Spigno, G., Tramelli, L. \& De Faveri, D. Effects of extraction time, temperature and solvent on concentration and antioxidant activity of grape marc phenolics. J. Food Eng. 81, 200-208 (2007).

18. Cvetanović, A. et al. Chemical and biological insights on aronia stems extracts obtained by different extraction techniques: From wastes to functional products. J. Supercrit. Fluids. 128, 173-181 (2017).

19. Gharaati, S. Extraction techniques of phenolic compounds from plants. Plant Physiol. Aspects Phenolic Comp. 2, 1-18 (2019).

20. Fan, R., Xiang, J., Li, N., Jiang, X. \& Gao, Y. Impact of extraction parameters on chemical composition and antioxidant activity of bioactive compounds from Chinese licorice (Glycyrrhiza uralensis Fisch.) by subcritical water. Sep. Sci. Technol. 51, 609-621 (2015).

21. Veličković, V. et al. Application of conventional and non-conventional extraction approaches for extraction of Erica carnea L.: Chemical profile and biological activity of obtained extracts. J. Supercrit. Fluids. 128, 331-337 (2017).

22. Inbaneson, S., Sundaram, R. \& Suganthi, P. In vitro antiplasmodial effect of ethanolic extracts of traditional medicinal plant Ocimum species against Plasmodium falciparum. Asian Pac. J. Trop. Med. 5, 103-106 (2012).

23. Casanova, L. et al. Identification of chicoric acid as a hypoglycemic agent from Ocimum gratissimum leaf extract in a biomonitoring in vivo study. Fitoterapia 93, 132-141 (2014).

24. Kfoury, M., Auezova, L., Ruellan, S., Greige-Gerges, H. \& Fourmentin, S. Complexation of estragole as pure compound and as main component of basil and tarragon essential oils with cyclodextrins. Carbohydr. Polym. 118, 156-164 (2015).

25. Kamimura, J., Santos, E., Hill, L. \& Gomes, C. Antimicrobial and antioxidant activities of carvacrol microencapsulated in hydroxypropyl-beta-cyclodextrin. LWT Food Sci. Technol. 57, 701-709 (2014).

26. Ngo, T., Scarlett, C., Bowyer, M., Ngo, P. \& Vuong, Q. Impact of different extraction solvents on bioactive compounds and antioxidant capacity from the root of Salacia chinensis L. J. Food Qual. 2017, 1-8 (2017).

27. Molaveisi, M., Beigbabaei, A., Akbari, E., Noghabi, M. \& Mohamadi, M. Kinetics of temperature effect on antioxidant activity, phenolic compounds and color of Iranian jujube honey. Heliyon. 5, e01129 (2019).

28. Wojdylo, A., Oszmianski, J. \& Czemerys, R. Antioxidant activity and phenolic compounds in 32 selected herbs. Food Chem. 105, 940-949 (2007).

29. Petrovic, M. et al. Antioxidant capacity determination of complex samples and individual phenolics-Multilateral approach. Combinat. Chem. High Throughput Screening. 19, 58-65 (2016).

30. Lima, J., Elizondo, N. \& Bohuon, P. Kinetics of ascorbic acid degradation and colour change in ground cashew apples treated at high temperatures $\left(100-180^{\circ} \mathrm{C}\right)$. Int. J. Food Sci. Technol. 45, 1724-1731 (2010).

31. Wang, W. \& Xu, S. Degradation kinetics of anthocyanins in blackberry juice and concentrate. J. Food Eng. 82, 271-275 (2007).

32. Mašković, P. et al. Summer savory extracts prepared by novel extraction methods resulted in enhanced biological activity. Ind. Crops prod. 109, 875-881 (2017). 


\section{Acknowledgements}

The authors wish to acknowledge the Cyprus International University Biotechnology Research Center for the technical support and the Grant awarded to conduct this research.

\section{Author contributions}

Conceptualization, O.C. and D.K.; methodology, O.C. software; validation, D.K.; formal analysis. O.C.; investigation, O.C.; resources, D.K.; data curation, D.K.; writing—original draft preparation, O.C.; writing—review and editing, D.K.; visualization, O.C. and D.K.; supervision, D.K.; project administration, D.K.; funding acquisition, D..K. All authors have read and agreed to the published version of the manuscript.

\section{Competing interests}

The authors declare no competing interests.

\section{Additional information}

Supplementary Information The online version contains supplementary material available at https://doi. org/10.1038/s41598-020-78847-5.

Correspondence and requests for materials should be addressed to C.O.

Reprints and permissions information is available at www.nature.com/reprints.

Publisher's note Springer Nature remains neutral with regard to jurisdictional claims in published maps and institutional affiliations.

Open Access This article is licensed under a Creative Commons Attribution 4.0 International License, which permits use, sharing, adaptation, distribution and reproduction in any medium or format, as long as you give appropriate credit to the original author(s) and the source, provide a link to the Creative Commons licence, and indicate if changes were made. The images or other third party material in this article are included in the article's Creative Commons licence, unless indicated otherwise in a credit line to the material. If material is not included in the article's Creative Commons licence and your intended use is not permitted by statutory regulation or exceeds the permitted use, you will need to obtain permission directly from the copyright holder. To view a copy of this licence, visit http://creativecommons.org/licenses/by/4.0/.

(C) The Author(s) 2020 